\title{
Influence of Exposing Root Canal Dentin to Calcium Hydroxide on Its Flexural Strength
}

\author{
Diatri Nari Ratih \\ Department of Conservative Dentistry, Faculty of Dentistry \\ Universitas Gadjah Mada, Yogyakarta, Indonesia \\ E-mail: trinaugm@yahoo.com \\ Received April 11, 2011; Accepted May 11, 2011
}

\begin{abstract}
Calcium hydroxide has been used extensively in endodontic treatments, for instance as an intra-canal dressing; however, the exposure of root canal dentin to calcium hydroxide may affect its flexural strength and could have important clinical implications for endodontic treatment. The purpose of this in vitro study was to investigate the influence of calcium hydroxide on the flexural strength of root canal dentin.

Seventy-two extracted single-rooted human mandibular premolars were used in this study. Each tooth was instrumented using crown-down technique and was irrigated using sterile saline. The teeth were assigned into three groups of 24 each. The prepared root canal system of each tooth was filled with calcium hydroxide mixed with sterile saline (group 1), a calcium hydroxide commercially available product (UltraCal ${ }^{\circ}$ ) (group 2) or saline solution (group 3, as control). The apices and access opening were sealed using composite resin, and the teeth were immersed in artificial saliva. After 7, 14 and 30 days of immersion, the inner root canal dentin of 8 teeth respectively from each group were sectioned to create dentin bars $(1 \times 1 \mathrm{~mm}$, with $7 \mathrm{~mm}$ in length). Each dentin bar then was subjected to a three-point bending flexural test using MTS (Universal Testing Machine). Data gathered were then analyzed using two-way ANOVA, followed by Tukey's test with the level of significance of $95 \%$.

The results showed that exposure to calcium hydroxide either using calcium hydroxide mixed with sterile saline or UltraCal ${ }^{\circ}$ for 14 and 30 days can reduce flexural strength of root canal dentin compared to control group $(p<0.05)$. In contrast, after 7 days exposure, there was no significantly different of flexural strength between three groups $(p>0.05)$.

It can be concluded that calcium hydroxide reduced the flexural strength of root canal dentin. The longer the exposure to calcium hydroxide would produce a greater effect on flexural strength of root canal dentin.
\end{abstract}

Keywords: Calcium hydroxide, root canal dentin, flexural strength, endodontic treatment.

\section{Introduction}

Root canal treatment is a common dental procedure with the aim is to retain teeth in which the pulp has become irreversibly infected or necrotic. A major goal of root canal treatment is to provide the complete decontamination of the root canal system. Root canal asepsis is attempted by a series of sequential steps of paramount importance, among which intracanal dressing is considered the most remarkable ${ }^{1}$.
Calcium hydroxide or $\mathrm{Ca}(\mathrm{OH})_{2}$ has been widely used in endodontic treatments, for instance as an intra-canal dressing. Placement of $\mathrm{Ca}(\mathrm{OH})_{2}$ during root canal treatment is a technique increasingly used in endodontic ${ }^{2}$. The beneficial effects of $\mathrm{Ca}(\mathrm{OH})_{2}$ are partly attributable to the hydroxyl alkalinizing properties during its diffusion through the dentin and partly to enhancing effects of $\mathrm{Ca}^{2+}$ in the formation of mineralized tissue ${ }^{3}$. When placed within the root canal system, $\mathrm{Ca}(\mathrm{OH})_{2}$ dissociates 
into calcium and hydroxyl ions, and the hydroxyl ions diffuse through the dentinal tubules ${ }^{4}$. The high $\mathrm{pH}$ and antimicrobial properties of $\mathrm{Ca}(\mathrm{OH})_{2}$ combined with the permeability of dentin may account its effectiveness as an intra-canal dressing ${ }^{5}$. Tatsuta et al. ${ }^{6}$ have showed proliferation of residual bacteria in root canal systems between appointments. Interappointments using $\mathrm{Ca}(\mathrm{OH})_{2}$ has been effective antimicrobial intra-canal dressing preventing proliferation of residual bacteria ${ }^{7}$.

Despite its beneficial effect of $\mathrm{Ca}(\mathrm{OH})_{2}$, it has been observed that $\mathrm{Ca}(\mathrm{OH})_{2}$ may be able to change the physical properties of dentin. For example, a 5-week exposure to $\mathrm{Ca}(\mathrm{OH})_{2}$ resulted in a $32 \%$ decrease in the strength of bovine dentin ${ }^{8}$. In sheep dentin treated with $\mathrm{Ca}(\mathrm{OH})_{2}$, a marked decrease in fracture strength with increasing storage time was observed ${ }^{9}$. Recent investigation showed that a reduction in the flexural strength of human dentin occurred when immersion in saturated solution of $\mathrm{Ca}(\mathrm{OH})_{2}$ for 1 week $^{5}$.

Several studies showed that $\mathrm{Ca}(\mathrm{OH})_{2}$ dissolved necrotic porcine muscle tissue, and pretreatment with $\mathrm{Ca}(\mathrm{OH})_{2}$ enhanced the tissue-dissolving effect of $\mathrm{NaOCl}^{10}$. Grigoratos et al. ${ }^{11}$ determined that $\mathrm{Ca}(\mathrm{OH})_{2}$ dissolved human pulp tissue, but more slowly than $\mathrm{NaOCl}$ as irrigation solution. Tatsua et $a . .^{6}$ found that $\mathrm{Ca}(\mathrm{OH})_{2}$ could erode intertubular dentin. This may have been due to $\mathrm{Ca}(\mathrm{OH})_{2}$ aiding in the dissolution of demineralized tissue by $\mathrm{NaOCl}$. Furthermore, Soares et $a .^{12}$ demonstrated that the combined action of $\mathrm{Ca}(\mathrm{OH})_{2}$ and $\mathrm{NaOCl}$ has a synergistic effect on tissue disintegration. Doyon et al. ${ }^{9}$ revealed that long term exposure to $\mathrm{Ca}(\mathrm{OH})_{2}$ altered the mechanical properties of dentin.

Dentin is composed of approximately $22 \%$ organic material by weight. Most of this consists of collagen type I, which contributes considerably to mechanical properties of dentin. Furthermore, the flexural strength of normal dentin is 212.9 $\pm 41.9 \mathrm{MPa}^{13}$. It would be reasonable to assume that the dissolution effect of $\mathrm{Ca}(\mathrm{OH})_{2}$ would affect dentin ${ }^{14}$. Therefore, exposure of root dentin to the bioactive effects of $\mathrm{Ca}(\mathrm{OH})_{2}$ may affect its mechanical properties of dentin and could have important clinical implications for endodontic treatments.
A common clinical problem affecting root canaltreated teeth is fracturing; this could require their extraction. Factors that predispose to fracture in endodontically treated teeth have been identified as changes in the mechanical properties of dentin due to medicaments used during root canal treatment ${ }^{15}$. In addition, the loss of structural integrity due to caries or access cavity preparation is attributed to the changes in the dentin mechanical properties ${ }^{11}$.

The influence of $\mathrm{Ca}(\mathrm{OH})_{2}$ as an intra-canal dressing during root canal treatment on the mechanical properties, particularly flexural strength of root canal dentin has not been reported. Furthermore, $\mathrm{Ca}(\mathrm{OH})_{2}$ as an inter-canal dressing needs to be contacted intimately to root canal wall. However, the length of the contact to the root canal wall needs to be investigated more. Therefore, the purpose of this in vitro study was to investigate the influence of $\mathrm{Ca}(\mathrm{OH})_{2}$ on the flexural strength of root canal dentin.

\section{Materials and Methods}

The project as approved bt the Ethics in Human Research Committee, University of Melbourne. Seventy-two intact, caries and crack free, extracted single-rooted human mandibular premolars, which stored in a $0.2 \%$ thymol solution were sectioned transversally using diamond cutting disk (Edenta, Swiss) to obtain 18-mm long roots. Each tooth was accessed coronally with an access bur (Dentsply, Maillefer, Ballaigues, Switzerland). The canals were instrumented to a size $20 \mathrm{~K}$ file (Dentsply Maillefer, Ballaigues, Switzerland) so that the file extended beyond the apical foramen by $1 \mathrm{~mm}$. The canals were then instrumented using Crown-down technique with ProTaper hand-used (Dentsply, Maillefer, Ballaigues, Switzerland). The canals were finished to a size F3. All files were extended $1 \mathrm{~mm}$ beyond the apical foramen and copious irrigation with sterile saline (Otsuka, Jakarta, Indonesia) to remove any dentin debris remaining in the canal after instrumentation.

The teeth then were assigned into 3 groups of 24 each. Group 1: the prepared root canal system was filled with $\mathrm{Ca}(\mathrm{OH})_{2}$ (Sigma Aldrich, Darmstadt, 
Germany) mixed with sterile saline; Group 2: filled with $\mathrm{Ca}(\mathrm{OH})_{2}$, commercial product (UltraCal', Ultradent, South Jordan, USA); Group 3: with saline solution only, which served as control. In Group 1, to ensure the intimate contact with the canal walls and a dense fill of the canal space, excess $\mathrm{Ca}(\mathrm{OH})_{2}$ was intentionally past the apex using lentulo spiral (Dentsply Maillefer, Ballaigues, Switzerland). In Group 2, the canals were densely filled by extruding the material through the apex using the syringe and plastic tip supplied. All teeth in all groups were sealed apically with bonded composite (Solare, GC, Tokyo, Japan) and coronally with a cotton pellet and bonded composite. Subsequently, the teeth were immersed in artificial saliva and were stored in an incubator with the temperature maintained at $37^{\circ} \mathrm{C}$.

After 7 days of immersion, the inner root canal dentin of 8 teeth from each group were removed from the artificial saliva containers and were sectioned to create dentin bars $(1 \times 1 \mathrm{~mm}$, with 7 $\mathrm{mm}$ in length). The bars were then tested on a threepoint bend testing apparatus using MTS Universal Testing Machine (Type AMU-5-DE, Tokyo Testing Machine, MFG, Co., Ltd., Tokyo, Japan) at a crosshead speed of $1 \mathrm{~mm} / \mathrm{min}$. The width and thickness of dentin bars were measured using an electronic caliper (Mitutoyo, Japan), and then the specimens were positioned on two points to create a 5-mm test span with the cross-head centered in this span. The test machine software automatically recorded the peak load at fracture. The mode of fracture was recorded as complete or incomplete fracture.

After 14 and 30 days of immersion, the remaining teeth from each group were removed from the artificial saliva containers and tested in the same manner as the 7-day group.

The flexural strength (in MPa unit) was calculated from the following equation:
Stress $=(3 \times$ Load $X$ Length $) /\left(2 \times\right.$ Width $X$ Thickness $\left.^{2}\right)$

The flexural strength data were analyzed statistically using two-way ANOVA, and the comparisons of means were conducted using Tukey's HSD. The analysis was performed at the 0.05 level of significance (Minitab Inc., State College, PA, USA).

\section{Results and Discussion}

The means and standard deviations of flexural strength of all groups were listed in Table 1. Compared to the control, $\mathrm{Ca}(\mathrm{OH})_{2}$ mixed with sterile saline (Group 1) as well as UltraCal ${ }^{\circledR}$ (Group 2) decreased the flexural strength either immersed for 7, 14 and 30 days. The results also indicated that Group 1 had the lowest flexural strength compared to the other groups. Immersion time for 30 days demonstrated the lowest flexural strength than the other immersion times. The results also revealed that the flexural strength of dentin slightly decrease in the control group when comparing to normal dentin (212.9 $\pm 41.9 \mathrm{MPa})$.

Two-way ANOVA showed that $\mathrm{Ca}(\mathrm{OH})_{2}$ either mixed with saline or UltraCal ${ }^{\circledast}$ reduced flexural strength significantly $(p<0,05)$. Flexural strength of dentin also decreased significantly with increasing the immersion time $(p<0,05)$. The longer the immersion time produced the lowest flexural strength. There is no interaction between intra-canal dressing groups and immersion time. Tukey's multiple comparison test demonstrated statistically significant differences among all groups $(p<0.05)$.

The results of this study showed that $\mathrm{Ca}(\mathrm{OH})_{2}$ had the deleterious effects on human root dentin. Therefore, this study appears to support the contention that long term exposure to $\mathrm{Ca}(\mathrm{OH})_{2}$

Table 1. The means and standard deviations (Mean \pm SD) of the flexural strength of dentin for each group (in MPa)

\begin{tabular}{cccc}
\hline $\begin{array}{c}\text { Intra-canal dressing immersion } \\
\text { time (days) }\end{array}$ & $\begin{array}{c}\mathrm{Ca}(\mathrm{OH})_{2}+\text { saline } \\
\text { (A1) }\end{array}$ & $\begin{array}{c}\text { UltraCal } \\
\text { (A2) }\end{array}$ & $\begin{array}{c}\text { Saline } \\
\text { (A3) }\end{array}$ \\
\hline 7 (B1) & $189.74 \pm 10.83$ & $197.25 \pm 9.38$ & $211.13 \pm 18.58$ \\
14 (B2) & $163.85 \pm 15.44$ & $186.35 \pm 12.25$ & $208.87 \pm 20.59$ \\
30 (B3) & $145.72 \pm 17.83$ & $156.42 \pm 18.72$ & $203.26 \pm 16.76$ \\
\hline
\end{tabular}


Table 2. Statistical analysis using two-way ANOVA on flexural strength of dentin

\begin{tabular}{lccccc}
\hline Source of variation & df & SS & MS & F & p-value \\
\hline Between Group A & 2 & 56882.48 & 28441.24 & 103.83 & 0.000 \\
Between Group B & 2 & 62041.36 & 31020.68 & 113.25 & 0.000 \\
Interaction & 4 & 25628.24 & 6407.06 & 23.39 & 0.065 \\
Within & 63 & 17256.67 & 273.92 & & \\
Total & 71 & 161808.75 & & & \\
\hline
\end{tabular}

alters the mechanical properties of dentin ${ }^{9}$. Calcium hydroxide is a material used in root canal treatment of human teeth for intra-canal dressing due to its antimicrobial properties, and the use of this material is often over extended periods of time ${ }^{4}$. The flexural strength reduced in this study; this may a result of a change in the organic matrix since $\mathrm{Ca}(\mathrm{OH})_{2}$ can dissolve pulp tissue, a process that may occur by denaturation and hydrolysis ${ }^{8}$. In addition, the $\mathrm{pH}$ increase observed after exposure to $\mathrm{Ca}(\mathrm{OH})_{2}$ may also reduce the organic support of the dentin matrix. These processes may disrupt the interaction of the collagen fibrils and hydroxide crystals that could negatively influence the mechanical properties of dentin ${ }^{9}$.

The results also in agreement with the finding of Grigoratos et al. ${ }^{11}$ which demonstrated the use of $\mathrm{Ca}(\mathrm{OH})_{2}$ as long term intra-canal dressing generates clean root canals. It could be speculated that $\mathrm{Ca}(\mathrm{OH})_{2}$ may not only disrupt the structure within the tissue, but inside the root canal it may also separate the tissue from the dentinal walls ${ }^{3}$. Teeth treated with an intra-canal dressing of $\mathrm{Ca}(\mathrm{OH})_{2}$ showed no growth after bacterial sampling ${ }^{7}$. Conceivably, $\mathrm{Ca}(\mathrm{OH})_{2}$ not only has an antibacterial effect, but also it can dissolve tissue remnants that otherwise would have become substrate for bacteria ${ }^{10}$.

Exposure of the standardized dentin bars to $\mathrm{Ca}(\mathrm{OH})_{2}$ is more pronounce on the surface of the dentin bars without considerably affecting the bulk of the dentin ${ }^{11}$. Moreover, $\mathrm{Ca}(\mathrm{OH})_{2}$ does not penetrate very well, so most of its effect will probably limit to the surface ${ }^{15}$. Treatment with $\mathrm{Ca}(\mathrm{OH})_{2}$ could thus potentially enhance crack initiation and propagation on the surface of dentin rendering it more prone to fracture ${ }^{13}$. Previous investigators also demonstrated that $\mathrm{Ca}(\mathrm{OH})_{2}$ pastes inside the root canal was able to diffuse through dentin into the external medium ${ }^{12}$.

Seven-day exposure of $\mathrm{Ca}(\mathrm{OH})_{2}$ represented the clinical situation of an inter-appointment period. It was speculated that the longer time of exposure might enhance dissolving ability of $\mathrm{Ca}(\mathrm{OH})_{2}$ as revealed in this study that the longer the exposure to $\mathrm{Ca}(\mathrm{OH})_{2}$ i.e., 14 and 30 days produced the lower flexural strength ${ }^{16}$. Exposure of $\mathrm{Ca}(\mathrm{OH})_{2}$ for 7 days did not result different capability to eliminate microorganisms than the longer periods of exposure ${ }^{17}$. Therefore, it is recommended to use of intra-canal dressing with $\mathrm{Ca}(\mathrm{OH})_{2}$ for 7 days rather than the longer periods of exposure due to the deleterious effect on mechanical properties of dentin.

The results of this study showed that $\mathrm{Ca}(\mathrm{OH})_{2}$ mixed with saline generated more effect to flexural strength than $\mathrm{Ca}(\mathrm{OH})_{2}$ (UltraCal $\left.{ }^{\circ}\right)$. Therefore, the depth of penetration of the solution and pastes should also be taken into consideration. The mixture of $\mathrm{Ca}(\mathrm{OH})_{2}$ and saline penetrated better to root dentin than $\mathrm{Ca}(\mathrm{OH})_{2}$ commercial product due to the lower surface tension of the former. The reduction in surface tension increases the penetration capability of mixture to the dentin tubules, but provokes deleterious effect on the mechanical properties of dentin ${ }^{5}$. Consequently, most of its effect will probably limit to the surface. Exposure to $\mathrm{Ca}(\mathrm{OH})_{2}$ significantly reduced flexural strength as compared to flexural strength of normal dentin, which is 212.9 $\pm 41.9 \mathrm{MPa}^{13}$.

The use of saline as a control should be questioned. This study indicated that the flexural strength of dentin reduced in the exposure to saline. It is speculated that isotonic saline dissolved the 
tissue. Chlorine ion in the saline may have produced some solvent effects. Distilled water may function as a better control in the future studies ${ }^{9}$.

The clinical implications of this study indicated that the use of $\mathrm{Ca}(\mathrm{OH})_{2}$ as an intra-canal dressing is recommended no longer than 7 days due to its effect on flexural strength of dentin. Tatsua et al. ${ }^{6}$ reported that the intra-canal dressing using $\mathrm{Ca}(\mathrm{OH})_{2}$ left for 7 days, with subsequent instrumentation and $\mathrm{NaOCl}$ irrigation, cleaned molar canals and isthmuses, as well as an ultrasonic device.

It is evident that further studies should be undertaken on the combined effect of $\mathrm{Ca}(\mathrm{OH})_{2}$ and $\mathrm{NaOCl}$ on the properties of dentin; this is due to that $\mathrm{NaOCl}$ becomes popular as irrigation solution, however, $\mathrm{NaOCl}$ has a deleterious effect on the mechanical properties of dentin ${ }^{15}$.

\section{Conclusion}

It can be concluded that $\mathrm{Ca}(\mathrm{OH})_{2}$ reduced the flexural strength of root canal dentin. The longer the exposure to $\mathrm{Ca}(\mathrm{OH})_{2}$ would produce a greater effect on flexural strength of root canal dentin.

\section{Acknowledgement}

The author wishes to acknowledge Prof. Harold H. Messer and Dr. Joseph EA. Palamara for their assistance in this study.

\section{References}

1. Ruddle CJ. 2006. Pulp development, structure and function. In: Cohen S, Burns RS, Ed. Pathways of The Pulp $9^{\text {th }}$ ed. Mosby: 386-425.

2. Mohamadi FA. 2005. Calcium hydroxide: A Review. Int Dent J, 55: 293-301.

3. Yucel AC, Aksoy A, Guvenc D. 2007. The pH changes of calcium hydroxide mixed with six different vehicles. Oral Surg Oral Med Oral Path Oral Rad \& Endod, 20: 256-62.

4. Sathorn C, Parashos P, Messer H. 2007. Antibacterial efficacy of calcium hydrolysis intra-canal dressing: A systematic review and meta-analysis. Int Endod J, 40: 2-10.

5. Poorni $S$, Miglani R, Srinivasan MR, Indira R. 2009. Comparative evaluation of the $\mathrm{pH}$ of calci- um hydroxide mixed with five different vehicles: An in vitro study. India J Dent Res, 20: 17-20.

6. Tatsua CT, Morgan LA, Baumgartner C, Adey J. 1999. Effect of calcium hydroxide and four irrigation regimens on instrumented and uninstrumented canal wall topography. J Endod, 25: 93-6.

7. Marending $\mathrm{M}$, Stark WJ, Brunner TJ, Fisher J, Zehnder M. 2009. Comparative assessment of time-related bioactive glass and calcium hydroxide effects on mechanical properties of human root dentin. Dent Traumatol, 25: 126-9.

8. Kawamoto R, Kurokawa H, Takubo C, Shimamura Y. 2008. Change in elastic modulus of bovine dentine with exposure to a calcium hydroxide paste. J Dent, 8: 315-20.

9. Doyon GE, Dumsha T, Fraunhofer JA. 2005. Fracture resistance of human root dentin exposed to intracanal calcium hydroxide. J Endod, 31: 895-7.

10. Lee KW, Williams MC, Camps JJ. 2002. Adhesion of endodontic sealers to dentin and gutta-percha. J Endod, 28: 684-8.

11. Grigoratos D, Knowles J, Ng YL, Gulabivala K. 2001. Effect of exposing dentine to sodium hypochlorite and calcium hydroxide on its flexural strength and elastic modulus. Int Endod J, 34: 113-9.

12. Soares CJ, Santana FR, Silva NR, Petra JC, Pereira CA. 2007. Influence of the endodontic treatment on mechanical properties of root dentin. $J$ Endod, 33: 603-6.

13. Plotino G, Grande NM, Bedini R, Pameijer $\mathrm{CH}$, Somma F. 2007. Flexural properties of endodontic posts and human root dentin. Dent Mater, 23: 1129-35.

14. Dietschi D, Duc O, Krejci I, Sadan A. 2007. Biomechanical considerations for the restoration of endodontically treated teeth: A systematic review of the literature-part 1. Composition and micro and macrostructure alterations. Quintessence Int, 38: 733-40.

15. Machnick TK, Torabinejad M, Munoz CA, Shababang S. 2003. Effect of MTAD on flexural strength and modulus of elasticity of dentin. $J$ Endod, 29: 747-50.

16. Leonardo MR, Hernandez M, Silva L, Filho M. 2006. Effect of a calcium hydroxide-based root canal dressing on periapical repair in dogs: A histological study. Oral Surg Oral Med Oral Path Oral Rad \& Endod 102: 680-5.

17. Morgana EV, Zilio DM, Ferraz CC, Zaia AA, Filho FJ, Gomes BP. 2009. Concentration of hydrogen ions in several calcium hydroxide pastes over different periods of time. Braz Dent J, 20: 382-8. 